\title{
Selection of the scenarios of ozone pollution at southern Taiwan area utilizing principal component analysis
}

\author{
Tai-Yi Yu*, Len-Fu W. Chang \\ Graduate Institute of Environmental Engineering, National Taiwan University, 71, Chou-Shan, Taipei, Taiwan, Peoples Republic of China
}

Received 2 July 1999; received in revised form 27 December 1999; accepted 13 January 2000

\begin{abstract}
The monitoring data analysis performed in this investigation focuses mainly on selecting statistically representative scenarios of ozone pollution in southern Taiwan. Measured data of ozone employed in this analysis were obtained from the monitoring stations of Taiwan Environmental Protection Administration (TEPA). The multivariate statistical technique, principal component analysis (PCA), was proposed to screen the ozone scenarios. Kaiser's varimax rotation method was also employed to separate the study area into several homogenous influence regimes. The analysis of spatial average ozone profiles, backward trajectories and statistical analysis could reveal features of selected ozone scenarios. Analysis results indicated that the first four unrotated components and rotated components accounted for more than 70 and $70.8 \%$ of the total variance, respectively. The score of the first unrotated principal component above 7 is the screening threshold for ozone scenarios. Such ozone scenarios accounted for $14.2 \%$ of ozone stations number days with a low occurrence rate of $1.37 \%$. Varimax rotation method successfully separated southern Taiwan into four homogenous ozone subregions, contributing 33.9, 17.3, 12.1 and $2.5 \%$ of total the variances, respectively. Evaluating the backward trajectories and spatial ozone profiles revealed that weak westerly sea breeze is the dominant factor affecting the production of the high ozone event for most stations. The backward trajectories also indicated similar meteorological patterns of the stations in the same subregion. (C) 2000 Elsevier Science Ltd. All rights reserved.
\end{abstract}

Keywords: Ozone pollution scenario; Principal component analysis; Varimax rotation method; Backward trajectory

\section{Introduction}

The ozone problem in a large metropolitan area is extremely complex. The emission characteristics and meteorological nature significantly contribute to the formation of a severe ozone episode. Thus, selection of representative scenarios of ozone pollution for a specific region and its use in designing the mitigation measures must be based on a sound-scientific procedure. The US National Research Council (1991) detailed state-of-art knowledge on the troposphere ozone problem. Selecting ozone scenarios involves consideration of the following factors. First, such scenarios should represent the most

\footnotetext{
* Corresponding author.

E-mail address: d2507005@ms31.hinet.net (T.-Yi. Yu).
}

likely meteorological conditions related to previous ozone events and are expected to occur in the future if not controlled. Second, the scenarios must be selected to provide further insight into the causal and consequential relationship between emission sources and affected air quality. Doing so allows us to formulate an effective mitigation strategy.

Southern Taiwan, known for its severe ozone problems, consists of five juridical regions: Kaoshuing City, Kaoshuing County, Tainan City, Tainan County and Pingtung County. Air-quality monitoring results obtained from Taiwan Environmental Protection Administration (TEPA), 1998 indicate that ozone episodes occur most frequently during autumn. Chang et al. (1996) attributed this situation to profound combinations of meteorological and emission characteristics of that region. Despite the sufficient solar irradiation, high concentrations of ozone seldom occur in southern Taiwan during 
the summer. The autumn ozone event is typically related to a certain meteorological flow pattern. When a weather situation favors a weak northerly wind at night and is followed by a weak westerly sea breeze developing during the day in southern Taiwan, high concentrations of ozone are observed at both coastal and inland areas of southern Taiwan. Specific wind trajectories are assumed to be responsible for the carrying, accumulation and transformation of precursor matters emitted by densely populated and industrial districts along the coastal region of southern Taiwan, ultimately evolving into a general ozone event.

While attempting to resolve the ozone problem, TEPA (1998) set forth an agenda in its National Environmental Protection Plan, promising to decrease the frequency of violations of air-quality standard to a certain level by different milestone dates. Following the agenda, TEPA also undergoes a procedure to devise an air-quality management plan as a compilation of control measures that can effectively reduce the frequency of ozone violations to the promised level. In this study, we present a statistical method for screening ozone scenarios using the principal component analysis (PCA) method (Jolliffe, 1986; Malinowski, 1991). Conventional preferences of episode days emphasized the analysis of weather patterns (US Environmental Protection Agency (US EPA), 1991) or the upper extreme ozone values (Mayer et al., 1997). The former with its factitious bias easily caused different kinds of categories, thereby preventing statistical consistency and real-time analysis when using measured airquality data. The latter was inappropriate for Taiwan owing to the lack of an allowable extreme probability in the law. In Taiwan, the air-quality goals of criteria pollutants were presented as the total stations number days. If the daily 1-h maximum ozone concentration of one station exceeds the legal value, the stations number days would be noted as 1 ; two stations violate the aforementioned rule in the same day, the stations number days would be noted as 2. Herein, the selection of ozone scenarios should illustrate the statistically dominant patterns of stations number days. PCA method provides an effective means of achieving this goal and real-time analysis. The application of PCA to data sets not only produced statistically independent linear combinations of original variables, but also explained for most of the total variation with reduced dimensions. This method has been successfully applied to identify the dominant multivariate relationships presented in measured data. These relationships are also compared with these found in the model predictions. Ashbaugh et al. (1984) utilized PCA method to obtain spatial patterns of the inter-site correlation of sulfur concentrations for 40 sites, in which the first two components accounted for $33.1 \%$ of the total variation. Three principal components accounted for $50 \%$ of the variance for the annual mean values of 17 pollutants in Los Angeles and New York (Henry and
Hidy, 1979). Smeyers-Verbeke et al. (1984) also used three principal components to illustrate $61,70,64$ and $54 \%$ of the variation in a data of 26 air pollutants at four places in the Netherlands, respectively. Poissant et al. (1996) applied PCA, rank and partial correlation analyses to show the relationships of 14 air pollutants and meteorological variables. In related investigations, Cohn and Dennis (1994) and Li et al. (1994) used PCA method to compare the model predictions and measured data by regional acid deposition model and the Eulerian acid deposition oxidant model.

Furthermore, analysis of hourly ozone contours, backward trajectories and statistical analysis provides further insight into the selected ozone scenarios and those characteristics from different aspects. To illustrate the specific geographical features of backward trajectories and hourly ozone contours, this study divided southern Taiwan into several classified influence regimes. Based on spatial ozone data, Rotated Principal Component Analysis (RPCA) can also provide useful spatial variability to separate southern Taiwan into several subregions. Eder (1989) and Eder et al. (1993) utilized the RPCA technique to analyze the $\mathrm{SO}_{4}^{2-}$ concentrations in precipitation and daily 1-h maximum ozone concentrations over non-urban areas over the eastern US; the station numbers were 40 and 77 . The application led to delineation of seven and six subregions for the former and later research, accounting for 74.2 and $64.02 \%$ of variance, respectively. As expected, the ozone scenarios selected by PCA procedure can reveal a clear meteorological effect on the impacted air quality, providing a basis for devising the mitigation strategy in southern Taiwan.

\section{Method and analysis procedure}

TEPA established the second-generation air-quality monitoring network in 1993. This network continuously monitors the air quality of Taiwan with a total of 71 stations. The major items of monitoring include the concentrations of $\mathrm{SO}_{2}, \mathrm{NO}, \mathrm{NO}_{2}, \mathrm{CO}, \mathrm{O}_{3}, \mathrm{PM}_{10}$ and NMHC. Some of the stations also provide meteorological reports, thereby enhancing the density of surface meteorological observational stations. As mentioned earlier, five juridical regions comprise the southern Taiwan area, with 17 stations monitoring the air quality. Fig. 1 illustrates the locations and the geographical coverage. The absorption of ultraviolet light was the measured technique for ozone. In this study, the historical data of hourly ozone concentrations are compiled into a database, with a time range of 1 July 1993-30 June 1998. This data set can be viewed mathematically as a time series of high-dimensional vectors, with each vector having 17 components (17 stations $\times 1825$ days $\times$ $24 \mathrm{~h})$ as its designation. 


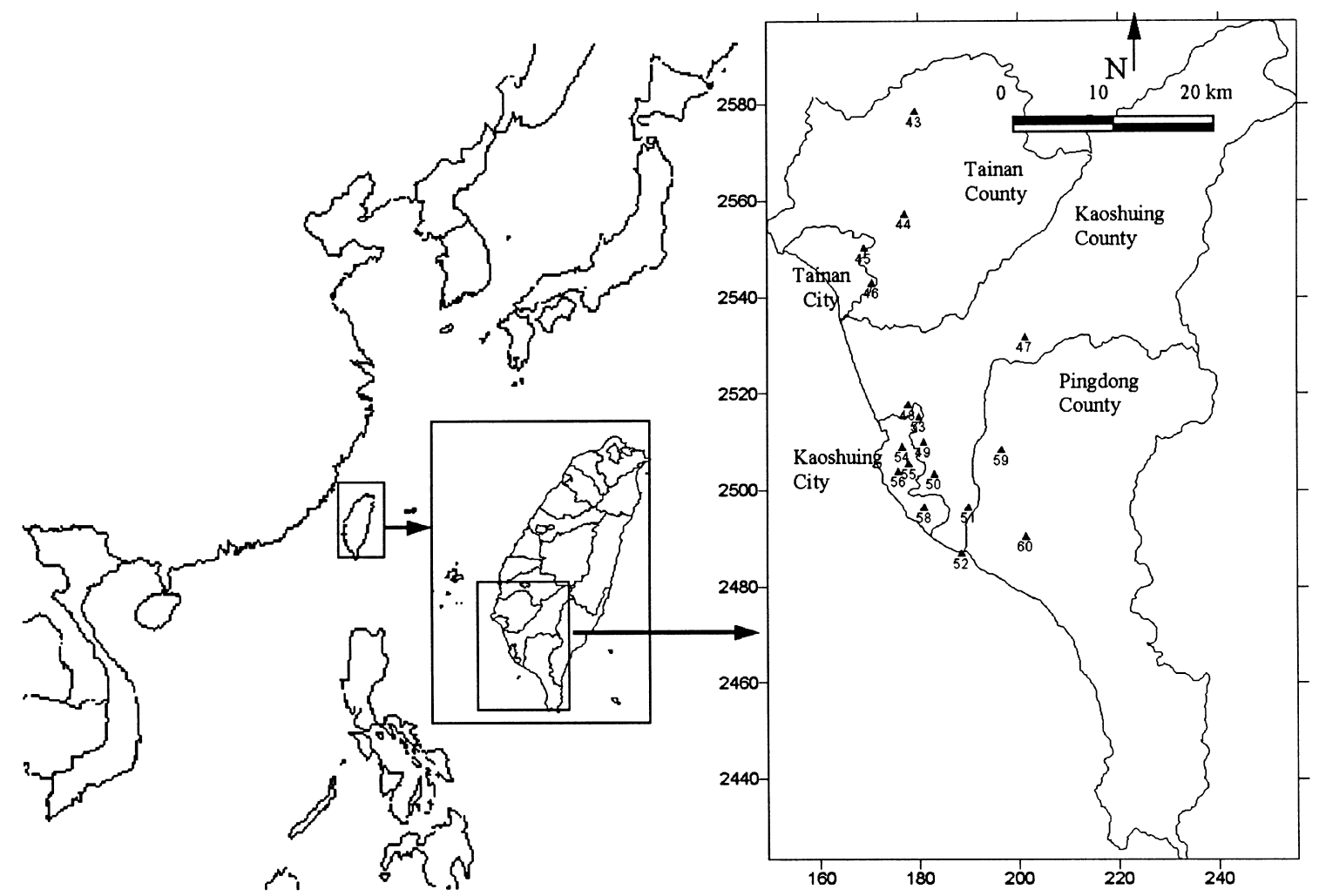

Fig. 1. Locations of the monitoring staions over southern Taiwan (Taiwan, ROC).

Furthermore, this study analyzed the measured hourly data of 1 and 2 PM during primary ozone days because these $2 \mathrm{~h}$ have the highest frequency to overcast the hourly legal value for ozone (120 ppb). Primary ozone days were defined as days in which at least three stations or more in southern Taiwan area reported an excess of $120 \mathrm{ppb}$ ozone hourly standards. We set the mean ozone concentrations to replace the missing values for 1 and 2 PM, respectively. The hourly data of 1 and 2 PM during primary ozone days were utilized for PCA and RPCA analysis. Seasonal distinctive variations could provide further insight into the features of primary ozone days. Correspondingly, the above-mentioned hourly data were classified into four data sets. (Spring: 1 March-31 May, summer: 1 June-31 August, autumn: 1 September-30 November and winter: 1 December-28 February).

PCA is a multivariate statistical tool used for reducing the dimensionality of a data set involving a large number of interrelated variables. Let the normalized value be given as

$Z_{i k}=\frac{C_{i k}-\mu_{i}}{S_{i}}$, where $Z_{i k}$ denotes the standardized value of the $k$ th observation on the $i$ th stations, $C_{i k}$ represents the $k$ th ozone concentration of the $i$ th station, $\mu_{i}$ is the mean value of the $i$ th station, and $S_{i}$ denotes the standard deviation of the $i$ th station. The use of a correlation matrix is much more suitable than a covariance matrix for resolving spatial oscillations. (Overland and Preisendorfer, 1982) Besides, the use of a correlation matrix presents the isopoleths of component loadings, which can be regarded as the correlation coefficients between the component and individual stations. The unrotated principal component model is

$Z_{i k}=\sum_{j=1}^{n} L_{i j} P_{j k}$

where $L_{i j}$ denotes the loading of the $i$ th station on the $j$ th unrotated principal component, and $P_{j k}$ represents the score of the $k$ th variable for the $j$ th unrotated principal component. Unrotated principal component can be derived by the inversion of (2)

$P_{j k}=\sum_{i=1}^{n}\left(L_{i j} / \lambda_{j}\right) Z_{i k}$ 
where $\lambda_{j}$ denotes the eigenvalue of the $j$ th unrotated principal component. The original data are transformed into a new set of orthogonal variables, the unrotated principal components, which are arranged with a decreasing order of explained variances. The unrotated principal components account for the maximum amount of variances with least number of factors in the data. The first unrotated principal component represents the maximum contribution of total variance. Horel (1981) indicated that the unrotated principal component solution depends on the domain of analysis. Without the rotation method, the highly dimensional components may have difficulty in underlining the physical meanings of unrotated components. The varimax rotation method, developed by Kaiser (1958), is a widely used orthogonal tool to separate subregions of homogenous ozone concentrations. In sum, the varimax method attempts to attain the maximum $Q$ value, as described in

$Q=n \sum_{j=1} \sum_{i=1}^{n}\left(\frac{A_{i j}}{h_{i}}\right)^{4}-\sum_{j=1}\left(\sum_{i=1}^{n} \frac{A_{i j}^{2}}{h_{i}^{2}}\right)^{2}$

$h_{i}^{2}=\sum_{j} A_{i j}^{2}$,

$Z_{i k}=\sum_{i=1}^{n} A_{i j} R_{j k}$

where $n$ denotes the numbers of station, $A_{i j}$ represents the loading of the $i$ th station on the $j$ th rotated principal component, $h_{i}$ is the communality of $i$ th station and $R_{j k}$ denotes the score of the $k$ th variable for the $j$ th rotated principal component. The procedure of the varimax technique aims to maximize the variances of the squared correlation coefficients between each rotated principal component and the time-series data. To further elucidate the interactions between stations' backward trajectories and possible subregions, this study employed the varimax rotation technique on hourly data of 1 and 2 PM during primary ozone days for all seasons. All statistical computations were employed with SPSS (version 7.0) software.

\section{Results}

The unrotated principal components were extracted while the eigenvalues are over 1 . Four and five principal components for spring and other seasons matched the aforementioned criterion. Table 1 displays the seasonal eigenvalues, explained variances, and cumulative variances for the first four unrotated principal components. In sum, the first component accounted for $28-43 \%$, the second for $17-25 \%$, the third for $10-17 \%$ and the fourth for $6-9 \%$ of the total variation of the data. The first four unrotated components account for $70 \%$ of variances for all seasons. The first unrotated component represents the
Table 1

Statistics for the first four unrotated principal components ${ }^{\mathrm{a}}$

\begin{tabular}{lrrrr}
\hline Spring & PC1 & PC2 & PC3 & PC4 \\
\hline Eigenvalue & 7.3 & 3.4 & 1.7 & 1.1 \\
Variation explained (\%) & 42.7 & 20.2 & 9.7 & 6.3 \\
Cumulative variances (\%) & 42.7 & 62.9 & 72.6 & 78.9 \\
Summer & & & & \\
Eigenvalue & 5.6 & 3.1 & 2.9 & 1.5 \\
Variation explained (\%) & 32.9 & 18.0 & 17.1 & 8.7 \\
Cumulative variances (\%) & 32.9 & 50.9 & 68.0 & 76.7 \\
Autumn & & & & \\
Eigenvalue & 5.5 & 2.8 & 2.1 & 1.6 \\
Variation explained (\%) & 32.2 & 16.6 & 12.5 & 9.3 \\
Cumulative variances (\%) & 32.2 & 48.8 & 61.2 & 70.6 \\
Winter & & & & \\
Eigenvalue & 4.7 & 4.2 & 1.8 & 1.6 \\
Variation explained (\%) & 27.9 & 24.5 & 10.8 & 9.3 \\
Cumulative variances (\%) & 27.9 & 52.4 & 63.2 & 72.5 \\
\hline
\end{tabular}

${ }^{\text {a }}$ Pci: the $i$ th unrotated principal component.

maximum variation of a data set. The higher the loading of a variable implies a larger contribution to the variation, accounting for the unrotated principal component. Table 2 reveals that the first four rotated principal components allow us to separate southern Taiwan area into four subregions. The varimax rotation method was used to assess the relative contribution of separated subregions. Each rotated principal component identified an influence regime that distinguished homogeneous ozone concentration subareas. Instead of drawing four maps, the combined map was obtained by plotting the highest loading of the four rotated principal components for each station. Herein, the unique subregions were divided by the 0.45 component loading isopleth. The first four influence regimes, which exhibit unique ozone concentration characteristics, accounted for $70.8 \%$ of total variance. Fig. 2 summarizes those results. Regions I, II, III and IV account for $33.9,17.3,12.1$ and $7.5 \%$ of the variation in data set, respectively. According to Table 3, the loadings of the first unrotated component of monitoring stations in areas I and II (the number of measured stations is 11) are positive for four seasons, except for station 48 . The positive loading of the component implies that the concentration of the measured station is above its mean value. This situation also reflects the positive correlation between the concentrations of these 11 stations and the score of first unrotated principal component. The higher the scores of the first unrotated principal component imply higher concentrations for most stations. The loading with value above $50 \%$ is the criterion to decide whether a rotated or unrotated principal component is significant for any station. Compared the rotated and unrotated principal components in Tables 2 and 3, every 
Table 2

The loadings of the first four rotated principal components ${ }^{\mathrm{a}}$

\begin{tabular}{llrrrr}
\hline Area & Station & \multicolumn{1}{l}{ PC1 } & \multicolumn{1}{l}{ PC2 } & \multicolumn{1}{l}{ PC3 } & \multicolumn{1}{l}{ PC4 } \\
\hline & 55 & 0.83 & 0.37 & 0.00 & 0.00 \\
& 56 & 0.78 & 0.32 & -0.47 & 0.05 \\
I & 54 & 0.89 & -0.12 & 0.04 & 0.07 \\
& 53 & 0.81 & 0.16 & 0.24 & 0.14 \\
& 50 & 0.62 & 0.57 & -0.14 & 0.03 \\
& 58 & 0.54 & 0.59 & -0.53 & 0.08 \\
& 49 & 0.85 & -0.03 & 0.13 & -0.23 \\
& 48 & 0.65 & 0.06 & 0.37 & -0.47 \\
II & 51 & 0.13 & 0.85 & 0.01 & -0.07 \\
& 52 & 0.13 & 0.80 & 0.01 & 0.12 \\
& 60 & -0.02 & 0.80 & 0.10 & 0.12 \\
III & 43 & 0.14 & 0.17 & 0.79 & 0.08 \\
& 44 & 0.00 & -0.03 & 0.80 & 0.10 \\
& 45 & 0.00 & 0.00 & 0.88 & -0.06 \\
\multicolumn{1}{l}{ IV } & 46 & 0.19 & -0.06 & 0.83 & -0.47 \\
& 47 & -0.01 & -0.02 & 0.09 & 0.82 \\
Eigenvalue & 59 & 0.12 & 0.17 & -0.40 & 0.77 \\
Variation & explained (\%) & 33.9 & 17.3 & 12.1 & 7.5 \\
Cumulative variances & 33.9 & 51.2 & 63.3 & 70.8 \\
(\%) & & & & & \\
& & & & &
\end{tabular}

${ }^{\text {a }}$ Pci : the loading of the $i$ th rotated principal component.

station in different separated areas is significant for unique rotated principal component, except for stations 50 and 58. Station 50 is more significant to PC1 than $\mathrm{PC} 2$ in rotated principal components, because the loading is 0.62 in PC1 and 0.57 in PC2. Due to the loading is 0.54 in $\mathrm{PC} 1$ and 0.59 in $\mathrm{PC} 2$, station 58 is the major reason for existing a little overlaps between regions I and II. Station 58 was categorized to region I by selecting the gridding method, the inverse distance to a second power. Table 3 shows that the loadings of station 55, 56, 50 and 58 in different seasons are significant to the first unrotated principal component. The loadings of other stations in different seasons are not significant to specific unrotated principal components, so the homogenous ozone areas could not be easily delineated by PCA method.

For primary ozone days, Fig. 3 plots the relationships between average stations number hours and the score of the first unrotated principal component. Similarly, if the hourly ozone concentration of one station exceeds the legal value, the stations number hours would be noted as 1 ; two stations violate the front rule in the same hour, the stations number hours would be denoted as 2 . The score of the first unrotated principal and then the seasonal average stations number hours for each interval was calculated. This graph revealed that the higher the score of the first unrotated principal component implies a

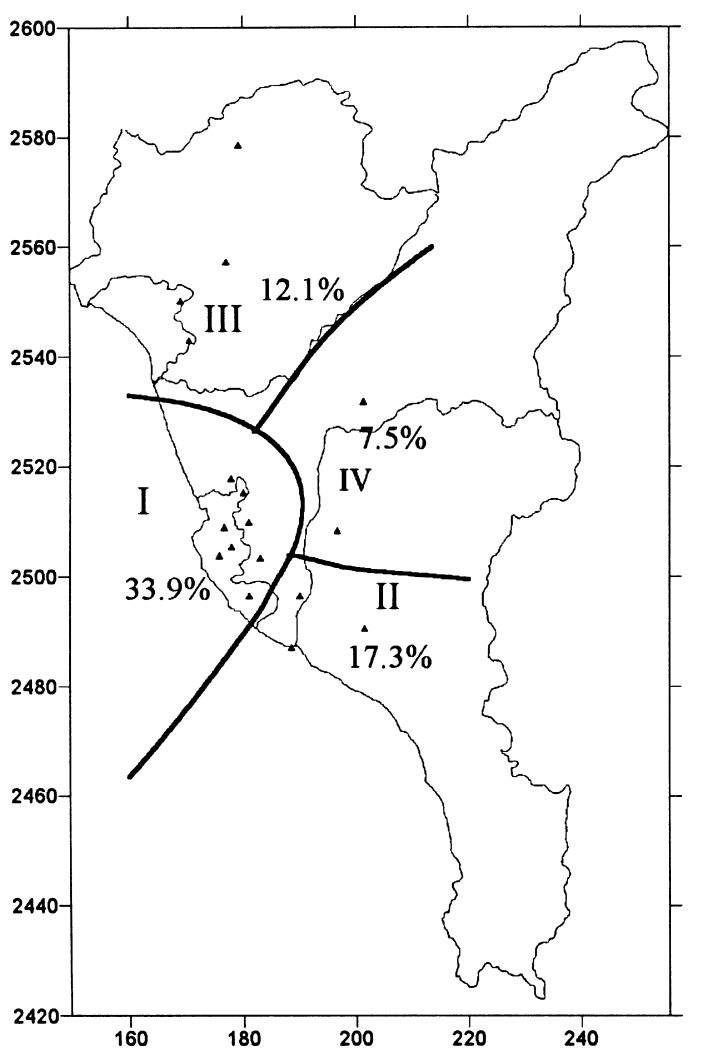

Fig. 2. Four homogenous ozone subregions.

larger average stations number hours. As the score of the first unrotated principal component is greater than 1 , autumn has the maximum average stations number hours for all intervals. While the score of the first unrotated principal component is greater than 7 , average stations number hours are greater than 4.5 for all seasons. Besides, the higher the scores of the first unrotated principal component indicated that 11 stations existed higher values above the mean concentrations of these stations. Therefore, the screening rule for ozone scenarios is defined as that in which the score of the first unrotated principal component is above 7 .

\subsection{Typical ozone concentration profiles}

Typical ozone concentration profiles and backward trajectories were analyzed to learn the characteristics of ozone scenarios. As mentioned earlier, the proceeding analysis revealed that autumn is the most ozone-polluted season in southern Taiwan. Therefore, the average ozone concentrations of autumn's ozone scenarios during 12 to 3 PM were shown in Fig. 4. At 12 PM, high ozone values exceeding $120 \mathrm{ppb}$ appear around seaside stations of area I. Then, all the stations of area I were covered with high 


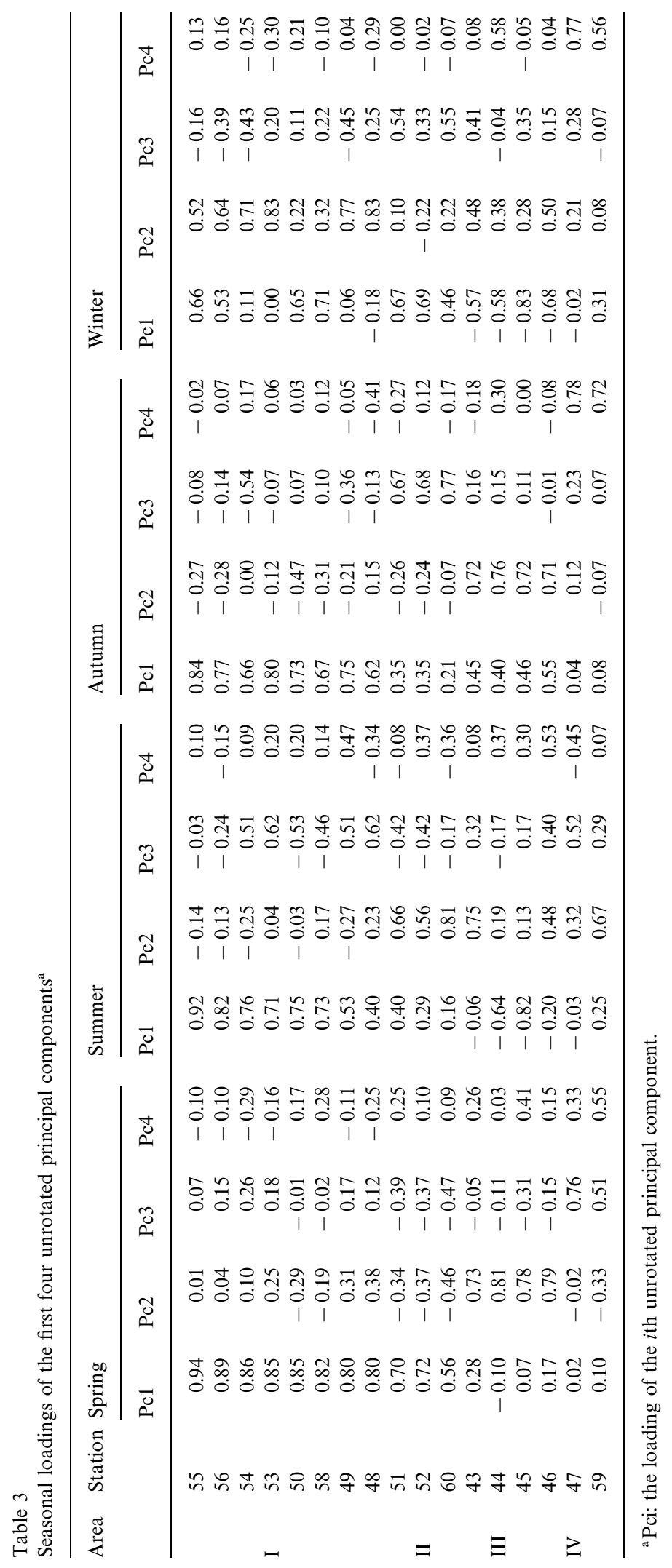




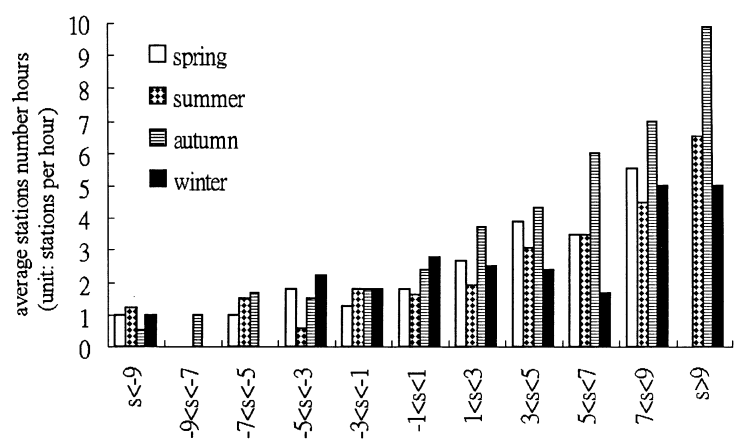

the scores of the first unrotated principal component

Fig. 3. Plot of stations number hours vs. the scores (S) of the first unrotated principal component.

ozone concentration at $1 \mathrm{PM}$. Due to the westerly sea breeze effects, the high-ozone district spreads over the whole region of areas I and II at 2 PM. At 3 PM, station 59 of area IV is the only one where high ozone value exists.

\subsection{Backward trajectories}

Backward trajectories provide a better diagram of the cause and consequence between the emission sources and the target station. Herein, the assimilation method, which incorporated Barnes objective method (Barnes, 1973) for interpolating spatial values and the variation-kinematical model (Chang et al., 1983), was adopted for correcting the effects of complex terrain, to produce the hourly wind fields data by using 70 surface stations over southern Taiwan. During ozone scenarios in autumn, the measured wind field data employed herein were from surface meteorological stations, two of the stations were from the Taiwan Central Weather Bureau (TCWB), and others were from TEPA. By utilizing the generated hourly wind fields at $200 \mathrm{~m}$ high over surface, backward trajectories were simulated from all monitoring stations. The trajectories were constructed using the horizontal wind components only. The trajectories have a segment resolution of $1 \mathrm{~min}$ and the interpolation was linear in time and space. The initial time of the backward trajectories for each station was set as the hour that the maximum average ozone concentration occurred.

Tsaur and Chang (1998) indicated that southern Taiwan was a $\mathrm{NO}_{x}$-limited region with the trajectory photochemical model. Therefore, in this study, the $\mathrm{NO}_{x}$ emission inventory of this area was plotted as a contrastive tool. As Fig. 5 indicates, the high $\mathrm{NO}_{x}$ emission inventory areas are along the coastal district of southern Taiwan. The backward trajectories of regions I, II and IV stations were categorized as three types and plotted in Fig. 5. In region I, the stations have the maximum average concentrations at $1 \mathrm{PM}$, region II at $2 \mathrm{PM}$ (except for station 51), region IV at $3 \mathrm{PM}$. As for the coastal stations of area I, the wind direction transfers to southwesterly at $11 \mathrm{AM}$ and the trajectories gradually travel to eastern side because of the weak westerly sea breeze effects. The trajectories of stations in region I are along with the coastal side of southern Taiwan, i.e. the dense $\mathrm{NO}_{x}$ polluted areas. The backward trajectories of region II stations have similar patterns.

The wind direction shifts to land at $10 \mathrm{AM}$, and the trajectories then travel to the inland area. In area IV, the air parcels travel long distances from the north side of southern Taiwan. With the weak sea wind, the polluted air parcels have sufficient time to stagnate at a high emission inventory area and form high ozone concentrations. In addition, the stations' trajectories of regions I and IV show the intercounty transport effects. Consequently, the weak westerly sea breeze is the prerequisite for forming these serious ozone events.

\subsection{Ozone station number days}

The aim of air quality was presented as the ratios of total stations number days in TEPA. To achieve the statistically dominant principal, Table 4 displays the seasonal ozone station number days for ozone scenarios; the ozone station number days is defined as the days whose PSI values are greater than 100 and the priority pollutants are ozone. Without any screening criteria, the average ozone station number days for autumn, spring, summer, winter and year are 1.42, 0.82, 0.46, 0.39 and 0.77 , respectively. At ozone scenarios, the average value of ozone station number days for autumn, spring, summer, winter and year are 9.3, 7.0, 6.0, 5.0 and 7.96, respectively. Area I has the maximum average ozone station number days during ozone scenarios. This phenomenon illustrates the dominant significance of area I, which contributes to the maximum variance in the data set. Although the low occurrence rate of ozone scenarios is $1.37 \%$ for $5 \mathrm{yr}$, this event covers $14.2 \%$ of ozone station number days.

\section{Conclusions}

This study has demonstrated that PCA can screen the statistically dominant ozone scenarios over southern Taiwan. PCA method is employed to analyze the characteristics of primary ozone days, in which at least three stations or more in southern Taiwan area exceed $120 \mathrm{ppb}$ ozone hourly standards. Data were collected from 1 July 1993 to 30 June 1998. The score of the first unrotated principal component above 7 was the screening rule for the ozone scenarios. When ozone scenarios occurred, the hourly ozone values for most monitoring stations exceeded $120 \mathrm{ppb}$. Other primary ozone days, which did 

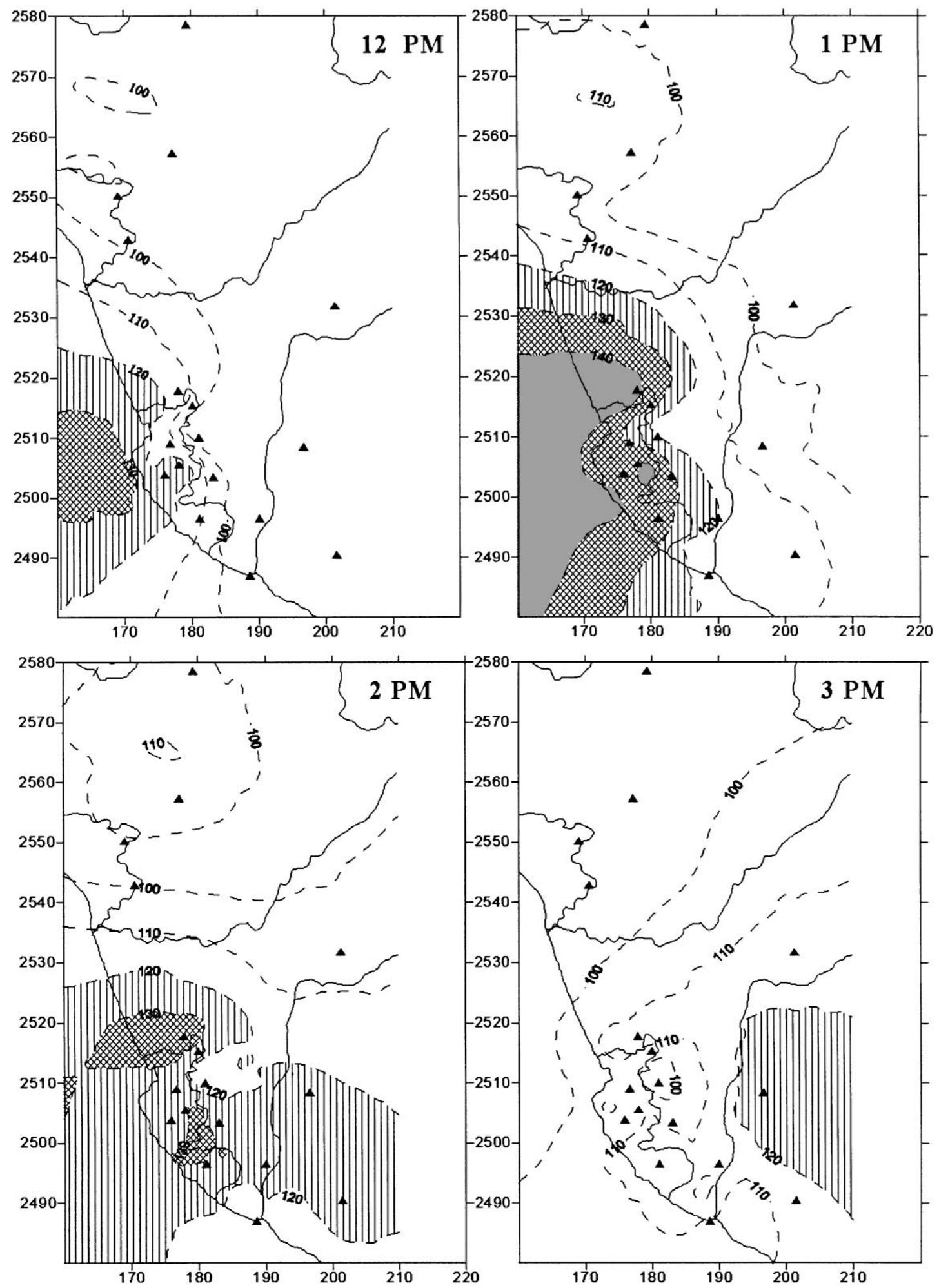

Fig. 4. Typical mean hourly ozone concentration for ozone scenarios in autumn (unit: ppb). 

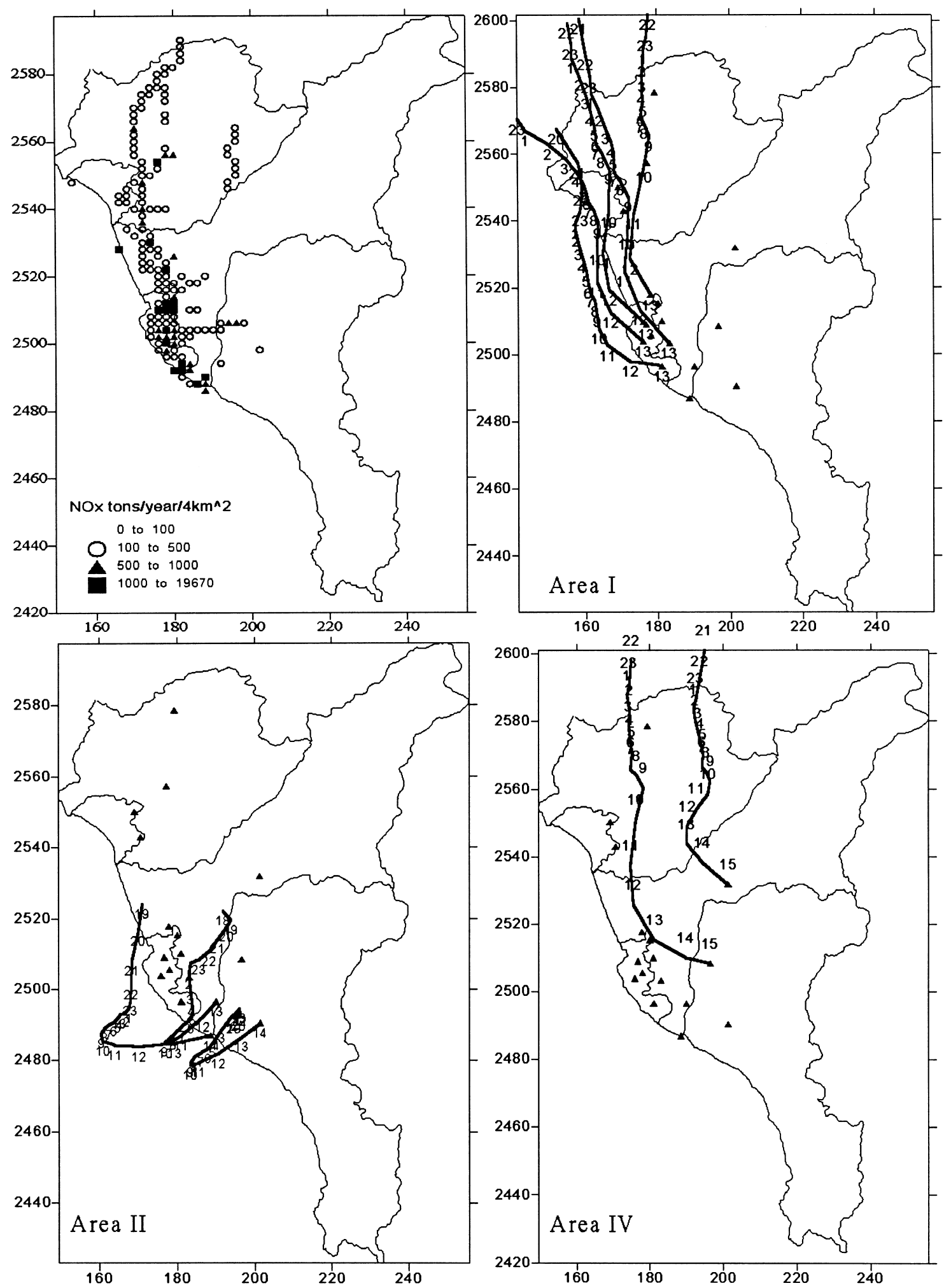

Fig. 5. Backward trajectories of the monitoring stations for different subareas (the numbers below the backward trajectories present the time). 
Table 4

Statistics for the ozone station number days ${ }^{\mathrm{a}}$

\begin{tabular}{|c|c|c|c|c|c|c|c|c|c|c|c|c|}
\hline \multirow[t]{2}{*}{ Area } & \multirow[t]{2}{*}{ Station } & \multicolumn{2}{|l|}{ Spring } & \multicolumn{2}{|l|}{ Summer } & \multicolumn{2}{|l|}{ Autumn } & \multicolumn{2}{|l|}{ Winter } & \multicolumn{3}{|c|}{ Summation } \\
\hline & & Severe $^{b}$ & General $^{\mathrm{c}}$ & Severe $^{b}$ & General $^{\mathrm{c}}$ & Severe $^{b}$ & General $^{\mathrm{c}}$ & Severe $^{b}$ & General $^{\mathrm{c}}$ & Severe $^{b}$ & General $^{\mathrm{c}}$ & Ratio $^{d}$ \\
\hline & 55 & 8 & 21 & 2 & 17 & 11 & 51 & 0 & 10 & 21 & 99 & 21.2 \\
\hline & 56 & 5 & 12 & 2 & 7 & 9 & 33 & 0 & 3 & 16 & 55 & 29.1 \\
\hline & 54 & 6 & 19 & 2 & 14 & 10 & 56 & 0 & 11 & 18 & 100 & 18.0 \\
\hline \multirow[t]{6}{*}{ I } & 53 & 6 & 18 & 0 & 8 & 11 & 29 & 0 & 8 & 17 & 63 & 27.0 \\
\hline & 50 & 4 & 13 & 1 & 16 & 8 & 31 & 1 & 6 & 14 & 66 & 21.2 \\
\hline & 58 & 7 & 19 & 0 & 13 & 8 & 37 & 1 & 6 & 16 & 75 & 21.3 \\
\hline & 49 & 4 & 9 & 2 & 6 & 6 & 17 & 0 & 4 & 12 & 36 & 33.3 \\
\hline & 48 & 7 & 20 & 1 & 22 & 11 & 57 & 0 & 15 & 19 & 114 & 16.7 \\
\hline & 51 & 5 & 31 & 0 & 16 & 8 & 59 & 1 & 13 & 14 & 119 & 11.8 \\
\hline \multirow[t]{3}{*}{ II } & 52 & 2 & 19 & 0 & 28 & 5 & 49 & 1 & 14 & 8 & 110 & 7.3 \\
\hline & 60 & 6 & 67 & 1 & 12 & 6 & 76 & 1 & 46 & 14 & 201 & 7.0 \\
\hline & 43 & 3 & 18 & 0 & 7 & 2 & 12 & 0 & 0 & 5 & 37 & 13.5 \\
\hline \multirow[t]{3}{*}{ III } & 44 & 0 & 7 & 0 & 3 & 1 & 20 & 0 & 3 & 1 & 33 & 3.0 \\
\hline & 45 & 2 & 13 & 0 & 3 & 2 & 10 & 0 & 4 & 4 & 30 & 13.3 \\
\hline & 46 & 0 & 12 & 0 & 3 & 2 & 11 & 0 & 3 & 2 & 29 & 6.9 \\
\hline \multirow[t]{5}{*}{ IV } & 47 & 1 & 30 & 1 & 12 & 4 & 22 & 0 & 7 & 6 & 71 & 8.5 \\
\hline & 59 & 4 & 47 & 0 & 24 & 8 & 74 & 0 & 22 & 12 & 167 & 7.2 \\
\hline & Total $^{\mathrm{e}}$ & 70 & 375 & 12 & 211 & 112 & 644 & 5 & 175 & 199 & 1405 & $14.2^{\mathrm{d}}$ \\
\hline & Days $^{\mathrm{f}}$ & 10 & 460 & 2 & 460 & 12 & 455 & 1 & 451 & 25 & 1826 & $1.37^{\mathrm{d}}$ \\
\hline & Average $^{g}$ & 7.0 & 0.82 & 6.0 & 0.46 & 9.3 & 1.42 & 5.0 & 0.39 & 7.96 & 0.77 & \\
\hline
\end{tabular}

${ }^{\text {a }}$ Ozone station number days is defined as the days those PSI values are greater than 100 and the priority pollutants are ozone.

${ }^{\mathrm{b}}$ The score of the first unrotated principal component is above 7 .

${ }^{\mathrm{c}}$ Without any screening criteria.

${ }^{\mathrm{d}}$ The ratio of severe ${ }^{\mathrm{b}}$ over general ${ }^{\mathrm{c}}$ in summation, unit: $\%$.

${ }^{\mathrm{e}}$ The summation of ozone station number days for all stations, unit: 'days.

${ }^{\mathrm{f}}$ Counted days, unit: days.

${ }^{\mathrm{g}}$ Average days of ozone station number days, $=$ total $^{\mathrm{e}} / \mathrm{days}^{\mathrm{f}}$.

not match the criteria of ozone scenarios, had scattered stations in which hourly ozone concentrations surpassed $120 \mathrm{ppb}$. The hourly ozone profiles, backward trajectories and statistical analysis revealed the characteristics of ozone scenarios. Based on hourly ozone profiles, the stations of regions I and II contained high ozone concentrations in which pollution was the significant attribute of ozone scenarios. The weak westerly sea breeze played an important role in producing high ozone concentrations for most stations by the analyses of backward trajectories. The backward trajectories of regions I and IVs' stations show the intercounty effects. As for the subregions separated by RPCA technique, backward trajectories of stations displayed the same meteorological flow patterns in the same subarea. The first four rotated components divided southern Taiwan into four areas and accounted for $33.9,17.3,12.1$ and $2.5 \%$ of total variances, respectively. The average value of ozone station number days is 7.96 for selected ozone scenarios, successfully accounting for $14.2 \%$ of overall ozone station number days with the low occurrence fraction of $1.37 \%$.
As mentioned earlier, selection of presenting scenarios of ozone pollution is the first task before completely evaluating ozone abated measures. Morereliable and statistical data are necessary for further investigation. Furthermore, more efficient use of airshed or trajectory photochemical models is necessary to assess the ozone reductions for alternative abatement strategies.

\section{References}

Ashbaugh, L.L., Myrup, L.O., Flocchini, R.G., 1984. A principal component analysis of sulfur concentrations in the western United States. Atmospheric Environment 18, 783-791.

Barnes, S.L., 1973. Mesoscale objective map analysis using weighted time series observations. NOAA Technical Memo. ERL NSSL-62, 60pp.

Chang, L.F.W., Hwang, R.R., Lin, S.C., 1983. A variation-kinematic model for flow over complex terrain. Annual Report of Institute of Physics. Academy Sinica 13, 89-102.

Chang, L.F.W., Lin, C.H., Jean, Y.B., Yu, T.Y., 1996. The characteristics of ozone pollution in the urban areas of northern and southern Taiwan. The Proceeding of the 13th Air 
Pollution Control Technologies Conference, Taipei, Taiwan, pp.1-12.

Cohn, R.D., Dennis, R.L., 1994. The evaluation of acid deposition models using principal component spaces. Atmospheric Environment 28, 2531-2543.

Eder, B.K., 1989. A principal component analysis of $\mathrm{SO}_{4}^{2-}$ precipitation concentrations over the eastern United States. Atmospheric Environment 23, 2739-2750.

Eder, B.K., Davis, J.M., Bloomfield, P., 1993. A characterization of the spatiotemporal variability of non-urban ozone concentrations over the eastern United States. Atmospheric Environment 27A, 2645-2668.

Henry, R.C., Hidy, G.M., 1979. Multivariate analysis of particulate sulfate and other air quality variables by principal components - part I annual data from Los Angeles and New York. Atmospheric Environment 13, 1581-1596.

Horel, J.D., 1981. A rotated principal component analysis of the interannual variability of the northern hemisphere $500 \mathrm{mb}$ height field. Monthly Weather Review 109, 2080-2092.

Jolliffe, I.T., 1986. Principal Component Analysis. Springer, New York.

Kaiser, H.F., 1958. The varimax criterion for analytic rotation in factor analysis. Psychometrika 23, 187-201.

Li, S., Anlauf, K.G., Wiebe, H.A., Bottenheim, J.W., Puckett, K.J., 1994. Evaluation of a comprehensive Eulerian air quality models with multiple chemical species measurements using principal component analysis. Atmospheric Environment 28, 3449-3461.

Malinowski, E.R., 1991. Factor Analysis in Chemistry, 2nd Edition. Wiley, New York.
Mayer, E.L., Baldridge, K.W., Chu, S., Cox, W.M., 1997. Choice of episodes to model: considering effects of control strategies on ranked severity of prospective episodes days. Air and Waste Management Association's 90th Annual Meeting Exhibition 97-MP112.01.

National Research Council, 1991. Rethinking the Ozone Problem in Urban and Regional Air Pollution. National Academy Press, Washington DC.

Overland, J.E., Preisendorfer, R.W., 1982. A significance test for principal components applied to a cyclone climatology. Monthly Weather Review 119, 1-4.

Poissant, L., Bottenheim, J.W., Roussel, P., Reid, N.W., Niki, H., 1996. Multivariate analysis of a 1992 Sontos data subset. Atmospheric Environment 30, 2133-2144.

Smeyers-Verbeke, J., Hartog, J.C.D., Dekker, W.H., Coomans, D., Buydens, L., Massart, D.L., 1984. The use of principal component analysis for the investigation of an organic air pollutants data sets. Atmospheric Environment 18, 2471-2478.

Taiwan Environmental Protection Administration (TEPA), 1998. National Environmental Protection Plan. http:// www.epa.gov.tw/.

Tsaur, C.H., Chang, L.F.W., 1998. Evaluation on the abated effectiveness of ozone precursor emissions in MIR scales by trajectory photochemical model. The Proceedings of 15 th Air Pollution Control Technologies Conference, Taipei, Taiwan, pp. 1-14.

US Environmental Protection Agency (US EPA), 1991. Guideline for Regulatory Application of Urban Airshed Models, EPA-450/4-91-013. 